\title{
STUDI DESKRIPTIF PENDAMPINGAN IBU HAMIL OLEH MAHASISWA DI KABUPATEN BREBES TAHUN 2018
}

\author{
Suci Utami \\ Akademi Kebidanan YPBHK Brebes \\ deandrahangkoso@yahoo.co.id
}

\begin{abstract}
Abstrak
Brebes merupakan Kabupaten yang berkontribusi dalam penurunan Angka Kematian Ibu, sehingga perlu langkah yang nyata antara lain dengan mengikutsertakan institusi pendidikan untuk melakukan pendampingan kepada ibu hamil. Mahasiswa diharapkan bisa menjadi patner tenaga kesehatan untuk memberikan edukasi dan memberi motivasi ibu hamil agar melakukan pemeriksaan secara rutin ke tenaga kesehatan. Peneliti menggunakan metode survey deskriptif dengan melihat gambaran pendampingan ibu hamil oleh mahasiswa di Kabupaten Brebes. Berdasarkan hasil penelitian 24 responden (100\%) memiliki Buku KIA dimana mahasiswa ikut meyakinkan ibu hamil pentingnya memiliki buku KIA., 22 responden $(91.78 \%)$ ibu terdampingi oleh mahasiswa saat kehamilan sebanyak > dari 4 kali, 17 responden $(70.83 \%)$ ibu bersalin yang terdampingi oleh mahasiswa saat proses persalinan, dan 18 responden $(75 \%)$ jenis pesalinan normal dengan 17 responden $(70,83 \%)$ di tolong oleh Bidan dan 10 Responden $(41,67 \%)$ pertolongan persalinan di lakukan di Puskesmas. Dari 24 responden yang didampingi oleh mahasiswa tidak ada kematian pada ibu dan bayi, 18 responden $(79,17)$ mendapatkan kunjungan oleh mahasiswa sebanyak 4 3kali dan 24 responden (100\%) mendapatkan pengawasan nifas sebanyak 4 kali. Institusi Pendidikan diharapkan lebih meningkatkan koordinasi multi sektoral, meliputi Dinas Kesehatan Kabupaten Brebes, Bidan dan tenaga pengajar agar program pendampingan ibu hamil oleh mahasiswa dilanjutkan secara berkesinambungan.
\end{abstract}

Kata Kunci : Pendampingan Ibu Hamil, Mahasiswa

\section{Pendahuluan}

Target MDGs di Indonesia masih belum tercapai salah satunya karena masih tinnggi Angka Kemtian Ibu (AKI). Untuk memastikan kesehatan ibu selama kehamilan dierlukan pelayanan antenatal (ANC) sehingga dapat menjamin ibu untuk melakukan persalinan di Fasilitas kesehatan. Dari $95 \%$ ibu hamil yang melakukan pelayanan antenatal di tenagakesehatan, terdapat $81,5 \%$ ibu hamil yang melakukan kunjungan minimal 4 kali selama kehamilan, tetapi hanya $65,5 \%$ yang melakukan empat kali kunjungan sesuai jadwal yang dianjurkan (woman research institusi, 2018)

Pemberian pelayanan kebidanan seharusnya dilakukan secara berkesinambungan (continuity of care), hal ini dilakukan dalam rangka memenuhi kebutuhan kebutuhan adaptasi ibu selama periode kehamilan, persalinan, dan nifas baik dari aspek fisik, psikologi dan social (Laliberté, Dunn, Pound, Sourial, Yasseen, Millar, \& Lacaze-Masmonteil, 2016).

Brebes merupakan Kabupaten yang berkontribusi dalam penurunan AngkaKematian Ibu, sehingga perlu langkah yang nyata antara lain dengan 
JURNAL ILMU KESEHATAN BHAKTI HUSADA:

HEALTH SCIENCES JOURNAL, VOL. 09 No. 01, JUNI 2018

DOI: $\underline{\text { https://doi.org/10.34305/jikbh.v9i1.60 }}$

mengikutsertakan institusi pendidikan untuk melakukan pendampingan kepada ibu hamil. Mahasiswa diharapkan bisa menjadi patner tenaga kesehatan untuk memberikan edukasi dan memberi motivasi ibu hamil agar melakukan pemeriksaan secara rutin ke tenaga kesehatan.

Mahasiswa berperan melakukan deteksi dini dan memantau perkembangan ibu hamil dengan resiko tinggi, memberikan pengetahuan tentang BPJS Kesehatan, termasuk mengantar ibu hamil bersalin ke Fasilitas kesehatan.

Kehamilan bukan menjadi permasalahan ibu sendiri, akan tetapi perlu melibatkan keluarga, masyarakat dan tenaga kesehatan. Oleh karena itu perlunya pendekatan penyelesaian masalah melakui kerjasama multisektor sangat diperlukan.

Program pendaampingan ibu hamil oleh mahasiswa bertuan untuk menerapkan konsep kebidanan dalam memberikan asuhan kebidanan secara professional dan efektif bagi klien, kegiatan ini dimulai sejak ibu diketahui hamil,melahirkan sampai masa nifas. Berdasarkan hal tersebut diatas maka peneliti tertarik untuk melakukan penelitian
Ciptaan disebarluaskan di bawah

Lisensi Creative Commons AtribusiNonKomersial-BerbagiSerupa 4.0 Internasional. Internasional.
Studi Deskriptif Pendampingan Ibu Hamil oleh Mahasiswa di Kabupaten Brebes.

\section{Metode Penelitian}

Peneliti menggunakan metode survey deskriptif dengan melihat gambaran pendampingan ibu hamil oleh mahasiswa di Kabupaten Brebes. Metode penelitian deskriptif digunakan untuk memecahkan atau menjawab permasalahan yang sedang dihadapi pada situasi sekarang (Notoatmodjo, 2005).

Kriteria sampel pada penelitian ini adalah semua ibu hamil yang didampingi oleh mahasiswa sampai dengan masa nifas dan didapatkan sampel sebanyak 24 responden.

Penelitian ini dilakukan dengan membagikan kuesioner dandata dianalisis menggunakan analisis deskriptif.

\section{Hasil dan Pembahasan}

Penelitian dilakukan pada 24 responden yaitu ibu hamil di Wilayah Kerja Puskesmas Kabupaten Brebes.

\section{Karakteristik Ibu Hamil}

Tabel 1. Karakteristik Ibu hamil

\begin{tabular}{lcc}
$\begin{array}{c}\text { Karakteristik Ibu } \\
\text { Hamil }\end{array}$ & Frekuensi & $\%$ \\
\hline Umur & 1 & 4,2 \\
\hline$<20$ tahun & 19 & 79,2 \\
\hline $21-35$ Tahun & 4 & 16,6 \\
\hline$<36$ tahun & & 75 \\
\hline Pendidikan & 18 & 20,8 \\
\hline Dasar & 5 & 4,2 \\
\hline Menengah & 1 & \\
\hline Tinggi & & 12,5 \\
\hline Pekerjaan & 3 & 87,5 \\
\hline Bekerja & 21 & 70,9 \\
\hline Tidak Bekerja & & 29,1 \\
\hline Kepemilikan BPJS & 17 & \\
\hline Ada & 7 & \\
\hline Tidak ada & & \\
&
\end{tabular}


JURNAL ILMU KESEHATAN BHAKTI HUSADA:

HEALTH SCIENCES JOURNAL, Vol. 09 No. 01, JUNI 2018

DOI: https://doi.org/10.34305/jikbh.v9i1.60
Ciptaan disebarluaskan di bawah

Lisensi Creative Commons AtribusiNonKomersial-BerbagiSerupa 4.0

Internasional. Internasional.
Berdasarkan umur menunjukkan 19 responden kelompok umur terbanyak adalah golongan umur 26-35 tahun $(79,2 \%)$ dibanding kelompok usia $<36$ tahun 4 responden $\quad(16,6 \%), \quad$ Berdasarkan pendidikan menunjukkan bahwa 18 respondenM $(75 \%)$ kelompok pendidikan dasar. Berdasarkan pekerjaan sebanyak 21 responden $(87.5 \%)$ ibu tidak bekerja dan berdasarkan kepemilikan BPJS 17 responden $(70.9 \%)$ memiliki asuransi kesehatan yaitu berupa BPJS Kesehatan

\section{a. Umur}

Berdasarkan hasil penelitian yang diperoleh dari pengolahan data terhadap 24 responden, bahwa usia ibu hamil saat pendampingan terbanyak pada kelompok usia 21-35 tahun yaitu 19 responden $(79,2 \%)$, responden dengan kelompok usia 26-35 tahun dianggap usia aman untuk hamil dan dianggap sebagai sudah dewasa dan cara berfikirnya yang sudah matang. Semakin matang usia seseorang akan semakin banyak pengalaman hidup yang dimiliki dan mudah untuk menerima perubahan perilaku, karena merupakan usia produktif dan paling ideal.

Adapun risiko yang mungkin terjadi jika hamil di bawah 20 tahun dan $>35$ tahun antara lain keguguran, preeklampsia (tekanan darah tiggi, oedema, proteinuria), eklampsia (keracunan kehamilan), timbulnya kesulitan persalinan karena sistem reproduksi belum sempurna, bayi lahir sebelum waktunya, Berat Badan Lahir Rendah (BBLR), fistula vesikovaginal (merembesnya air seni ke vagina), fistularetrovaginal (keluarnya gas dan tinja dari vagina) dan kanker leher rahim (Buku saku kebidanan, 2010)

\section{b. Pendidikan}

Berdasarkan hasil penelitian 18 respinden $(75 \%)$ masuk kedalam pendidikan rendah. Menurut Muslikhatun (2009) tingkat pendidikan dikaji untuk menyatakan tingkat intelektualnya. Tingkat pendidikan berpengaruh dalam pelyanan dalam menerima asuhan kebidanan. Tingkat pendidikan merupakan faktor yang mendasari pengambilan keputusan dan ditunjang oleh tingkat pengetahuan ibu tentang kesehatan dan kesadaran ibu sendiri akan pentingnya menjaga kehamilannya (Verdiani, dkk 2012).

\section{c. Pekerjaan}

Berdasarkan hasil penelitian 21 responden $(87,5 \%)$ ibu tidak bekerja, menurut Sujiyatini (2011 dalam walyani 2015) data pekerjaan menggambarkan tingkat sosial ekonomi, pola sosialisasi dan data pendukung dalam menentukan pola komunikasi yang akan dipilih selama asuhan. Seorang wanita hamil bisa mengerjakan pekerjaan sehari-hari apabila hal tersebut tidak memberikan gangguan rasa tidak enak.

\section{d. Kepemilikan Asuransi Kesehatan}

Berdasarkan hasil penelitian 17 responden $(70,9 \%)$ ibu memiliki jaminan kesehatan yaitu Bpjs Kesehatan. Jaminan kesehatan adalah jaminan berupa perlindungan kesehatan agar peserta memperoleh manfaat pemeliharaan kesehatan dan perlindungan dalam memenuhi kebutuhan dasar kesehatan yang diberikan kepada setiap orang yang telah membayar iuran atau iurannya dibayar oleh pemerintah.

Jaminan kesehatan nasional (JKN) merupakan bagian dari Sistem Jaminan Sosial Nasional (SJSN) yang diselenggarakan dengan menggunakan mekanisme asuransi kesehatan sosial yang bersifat wajib (mandatory) berdasarkan Undang-Undang Nomor 40 Tahun 2004 tentang SJSN dengan tujuan untuk memenuhi kebutuhan dasar kesehatan masyarakat yang layak yang diberikan kepada setiap orang yang telah membayar iuran atau iurannya telah dibayar oleh pemerintah (Perpres no 12 tahum 2013).

Jaminan kesehatan dalam hal ini BPJS Kesehatan memiliki manfaat yang sangat besar untuk ibu hamil dimana BPJS menyediakan layanan bagi pesertanya yang 
sedang dalam proses kehamilan hingga melahirkan, Layanan melahirkan tidak terbatas bagi peserta manapun. Hal ini dapat menolong ibu terutama yang dengan ekonomi rendah yang membutuhkan biaya banyak untuk proses persalinan normal maupun SC.

\section{Pendamping Ibu Hamil}

Tabel 2. Pendampingan Ibu Hamil

\begin{tabular}{lcc}
\hline Pendampingan Ibu Hamil & Frekuensi & $\%$ \\
\hline Kepemilikan Buku KIA & & \\
\hline Ada & 24 & 100 \\
\hline Tidak ada & 0 & 0 \\
\hline Stiker p4k & & \\
\hline Terpasang & 13 & 54,17 \\
\hline Tidak terpasang & 11 & 45,83 \\
\hline Kunjungan Kehamilan & & \\
\hline 2-3 kali & 2 & 8,22 \\
\hline >/4 Kali & 22 & 91,78 \\
\hline Pengawasan Kehamilan & & \\
\hline Ya & 24 & 100 \\
\hline Tidak & 0 & 0 \\
\hline
\end{tabular}

\section{a. Kepemilikan Buku KIA}

Berdasarkan hasil penelitian 24 responden (100\%) memiliki Buku KIA dimana mahasiswa ikut meyakinkan ibu hamil pentingnya memiliki buku KIA.

Fungsi buku KIA meningkat selain sebagai media KIE dan Dokumen pencatatan pelayanan KIA, buku KIA digunakan untuk mempermudah mendapatkan akte kelahiran, alatbukti yang digunakan pada system jaminan kesehatan dan bantuan program keluarga harapan $(\mathrm{PKH})$, mendukung implementasi kebijakan tertentu seperti persyaratan masuk TK atau SD, mempermudah pemahaman masyarakat tentang pemenuhan hak pelayanan KIA. (Petunjuk teknis penggunaan buku KIA,2015).

\section{b. Stiker P4K}

Berdasarkan hasil penelitian 13 responden $(54,17 \%)$ sudah terpasang stiker P4K, 11 respnden (45.82\%) tidak mau melakukan pemasangan stiker $\mathrm{P} 4 \mathrm{~K}$ dikarenakan faktor mitos
Mitos merupakan adat istiadat turun temurun dari orang tua, di Indonesia terutama di Jawa banyak mitos dan Tradisi yang sangat kuat diterapkan oleh masyarakat dan bisa dipercaya sebagai amanat nenek moyang yang jika tidak ditaati akan menimbulkan dampak yang tidak menyenangkan (Kusumandari 2010).

Ketrampilan komunikasi sangat penting dimiliki oleh setiap tenaga kesehatan yang melakukan kontak dengan ibu hamil dan keluarga dalam pengisian stiker. Mereka harus mampu memberikan penjelasan / konseling kepada keluarga tentang pentingnya perencanaan persalinan serta bagaimana mempersiapkan ibu hamil dan keluarga bila terjadi komplikasi, persalinan dan nifas (Pedoman P4K dengan stiker,2009)

\section{c. Kunjungan Kehamilan oleh Mahasiswa}

Berdasarkan hasil penelitian 22 responden $(91.78 \%)$ ibu terdampingi oleh mahasiswa saat kehamilan sebanyak > dari 4 kali, Pendampingan kehamilan dilakukan dengan mahasiswa datang ke rumah ibu 
JURNAL ILMU KESEHATAN BHAKTI HUSADA:

HEALTH SCIENCES JOURNAL, Vol. 09 No. 01, JUNI 2018

DOI: $\underline{\text { https://doi.org/10.34305/jikbh.v9i1.60 }}$

hamil untuk memastikan kondisi ibu dan janin dalam keadaan sehat, dan 24 (100\%) responden meastikan pengawasan kehamilan, memastikan tidak ada tanda bahaya kehamilan dan mengatasi keluhan yang terjadi. Pelayanan ANC menurut Mizumoto et al (2015) dapat meningkatkan kesejahteraan ibu dan janin. WHO merekomendasikan bahwa setiap ibu hamil
Ciptaan disebarluaskan di bawah

Lisensi Creative Commons AtribusiNonKomersial-BerbagiSerupa 4.0 Internasional. Internasional. diwajibkan untuk melakukan kunjungan ke petugas kesehatan minimal 4 kali. Pendekatan identifikasi terhadap resiko terhadap risiko bukan alas an penting, tetapi persiapan pengetahuan ibu hamil dapat lebih meningkatkan kesejahteraan ibu dan janin (Ayiasi, Kasasa, Criel et al 2014 dalam Yulianti, et al 2016);

\section{Pendamping Persalinan}

Tabel 3. Pendampingan Persalinan

\begin{tabular}{lcc}
\multicolumn{1}{c}{ Pendampingan Ibu Bersalin } & Frekuensi & \% \\
Pendampingan persalinan & & \\
\hline Melakukan & 17 & 70,83 \\
\hline Tidak melakukan & 7 & 29,17 \\
\hline Jenis Persalinan & & \\
\hline Normal & 18 & 75 \\
\hline Dengan Alat & 1 & 4,17 \\
\hline SC & 5 & 20,83 \\
\hline Penolong & & \\
\hline Bidan & 17 & 70,83 \\
\hline Dokter & 6 & 29.17 \\
\hline Tempat Pesalinan & & \\
\hline RS & 9 & 70.83 \\
\hline PKM & 10 & 41.67 \\
\hline BPM & 5 & 12.50 \\
\hline
\end{tabular}

Berdasarkan hasil penelitian 17 responden $(70.83 \%)$ ibu bersalin yang terdampingi oleh mahasiswa saat proses persalinan, dan 18 responden $(75 \%)$ jenis pesalinan normal dengan 17 responden $(70,83 \%)$ di tolong oleh Bidan dan 10 Responden $(41,67 \%)$ pertolongan persalinan di lakukan di Puskesmas. Dari 24 responden yang didampingi oleh mahasiswa tidak ada kematian pada ibu dan bayi.

Pendampingan ibu hamil oleh mahasiswa secara berkesinambungan dapat mengurangi intervensi medis obstetric selama persalinan dan menurunkan angka kematian Ibu dan anak. ((Iravani, et al, 2015 dalam Yulianti, et al 2016).

Salah satu prinsip dasar asuhan sayang ibu adalah mengikutsertakan suami dan keluarga selama proses persalinan dan kelahiran bayi. Banyak hasil penelitian menunjukkan bahwa para ibu yang diperhatikan dan diberi dukungan selama persalinan dan kelahiran bayi, serta mengetahui dengan baik proses persalinan dan asuhan yang akan mereka terima, mendapatkan rasa aman dan penampilan yang lebih baik (Enkin, et al, 2000 dalam Yulianti, et al 2016). Disebutkan juga bahwa asuhan tersebut dapat mengurangi jumlah persalinan dengan tindakan seperti ekstraksi vakum, cunam, dan seksio cesarea/Caesar. Selain itu, asuhan ini juga dapat membuat persalinan berlangsung lebih cepat. (Enkin, et al, 2000 dalam Yulianti, et al 2016).

Dukungan dalam persalinan dapat berupa pujian, penentraman hati, tindakan 
untuk meningkatkan kenyamanan ibu, kontak fisik, penjelasan tentang yang terjadi selama persalinan dan kelahiran, serta sikap ramah yang konstan. Tugastugas tersebut dapat dipenuhi oleh bidan. Namun, pada praktiknya bidan juga harus melakukan prosedur medis yang dapat mengalihkan perhatian mereka dari si ibu. (Nike Badhi Subeki, SKp, 2003 dalam dalam Yulianti, et al 2016). Oleh karena itu, seorang perempuan yang bersalin harus ditemani orang yang ia percayai dan dapat membuatnya merasa nyaman, bisa pasangan/suami, sahabat, atau anggota keluarga dekat lainnya, dalam hal ini mahasiswa sudah mempuyai ikatan kuat dengan ibu hamil, dimana saat persalinan ibu menghubungi mahasiswa untuk melakukan pendampingan.

\section{Pendamping Nifas}

Tabel 4. Pendampingan Nifas

\begin{tabular}{lcc}
\hline $\begin{array}{c}\text { Pendampingan } \\
\text { Ibu Nifas }\end{array}$ & Frekuensi & $\%$ \\
\hline $\begin{array}{l}\text { Kunjungan Ibu } \\
\text { Nifas }\end{array}$ & & \\
\hline $\mathbf{2 x}$ & 5 & 20,83 \\
\hline$>\mathbf{4 x}$ & 18 & 79,17 \\
\hline Pengawasan Nifas & & \\
\hline Dilakukan & 24 & 100 \\
\hline Tidak dilakukan & 0 & 0 \\
\hline
\end{tabular}

Berdasarkan hasil penelitian, 18 responden $(79,17)$ mendapatkan kunjungan oleh mahasiswa sebanyak $43 \mathrm{kali}$ dan 24 responden $(100 \%)$ mendapatkan pengawasan nifas sebanyak 4 kali berupa menanyakan kondisi secara umum, melakukan pengukuran TFU, melakukan pemeriksaan lokia dan perdarahan, melakukan pemeriksaan kondisi jalan lahir dan tanda infeksi, pemeriksaan payudara, pemberian ASI Eksklusif, Pendidikan Kesehatan kontrasepsi pasca salin, konseling dan nasihat pada ibu nifas.

Klien terlibat penuh dalam perencanaan waktu dan proses pendampingan oleh mahasiswa dalam pemberian asuhan mulai dari kunjungan kehamilan, pendampingan persalinan sampai kunjungan nifas yang memenuhi atau menyesuaikan kebutuhan fisik, psikologis dan spiritual ibu, bayi dan keluarga.

Permasalahan-permasalahan yang dialami oleh ibu nifas dapat ditangani dengan pendampingan yang baik dari keluarga dan petugas kesehatan (soltani
2015 dalam Yulianti, et al 2016). Adaptasi ibu dalam menghadapi peran barunya dapat berjalan lebih cepat dengan pendampingan oleh keluarga dan tenaga kesehatan.

\section{Kesimpulan dan Saran}

\section{Kesimpulan}

a. Usia responden 21-35tahun sebanyak 19 responden $(79,2 \%)$ ibu hamil, 18 responden $(75 \%)$ ada pada pendidikan dasar, 21 responden $(87,5$ $\%$ ) tidak bekerja dan 17 responden (70,9\%) memiliki kepesertaan BPJS Kesehatan.

b. Pendampingan ibu hamil ada 24 responden $(100 \%)$ sudah memiliki buku KIA, 13 responden $(54,17 \%)$ sudah terpasang stiker P4K, 22 responden $(91,78 \%)$ terdampingi oleh mahasiswa sebanyak > 4 kali dan $100 \%$ mahasiswa melakukan pengawasan kehamilan.

c. Pendampingan persalinan 17 responden $(70,83 \%)$ mahasiswa melakukan pendampingan, 18 
responden $(75 \%)$ bersalin normal dengan 17 responden $(70,83 \%)$ ditolong oleh bidan dan 10 responden $(41,67 \%)$ tempat persalinan di lakukan di Puskesmas.

d. Pendampingan nifas 18 responden $(79,17)$ terdampingi oleh mahasiswa dan 24 responden (100\%) mahasiswa melakukan pengawasan nifas.

\section{Saran}

Lebih meningkatkan koordinasi multi sektoral, meliputi Dinas Kesehatan Kabupaten Brebes, Bidan dan tenaga pengajar di Institusi Pendidikan agar program pendampingan ibu hamil oleh mahasiswa dilanjutkan secara berkesinambungan.

\section{Daftar Pustaka}

Meiliya, Eni., Esti Wahyuningsih. (2010). Buku Saku Kebidanan. Jakarta : Buku Kedokteran EGC.

Kusumandari, Winda. (2010). Bidan sebuah Pendekatan Midwifery of Knowledge. Yogyakarta Nuhamedika.

Laliberté, C., Dunn, S., Pound, C., Sourial, N., Yasseen III, A.,S., Millar, D., \& Lacaze-Masmonteil, T. (2016). A randomized controlled trial of innovative postpartum care model for mother-baby dyads. PLoS One, 11(2) doi:http://dx.doi.org/10.1371/journ al.pone.0148520.

Notoatmodjo, S. (2010). Metodologi penelitian kesehatan. Jakarta : PT Rineka Cipta.

Pedoman Program Perencanaan Persalinan dan Pencegahan Komplikasi dengan Stiker. (2009).

Peraturan Menteri kesehatan RI No.71 Tahun 2013 tentang Pelayanan Kesehatan Nasional. (2013).

Petunjuk Teknis Penggunaan Buku Kesehatan Ibu dan anak . (2015).
Sujiyatini. (2011). Asuhan Kebidanan II (Persalinan). Yogyakarta : Rohima press.

Woman Reseach Institute. (2018). Mengurangi Angka Kematian Ibu (Editorial). Diakses pada $30 \mathrm{mei}$, 2018, from http://www.wri.or.id/editorial/11mengurangi-angka-kematianibu\#.WxdCOPmFPIV

Walyani, ES. (2015). Asuhan Kebidanan Pada Kehamilan. Yogyakarta : Pustaka Baru Press.

Verdani., dkk. (2012).Gambaran Karakteristik Ibu Hamil pada Persalinan Preterm di RSUP Dr. M. Djamil Padang Tahun 2012.

Yuliani A, et al. (2016) Pendampingan Ibu hamil melalui Program OSOC di Wilayah Kerja Genuk Semarang. 